\title{
Note sur la translittération
}

Philippe Bornet et Svetlana Gorshenina

\section{OpenEdition}

Journals

Édition électronique

URL : http://journals.openedition.org/edl/638

DOI : $10.4000 /$ edl. 638

ISSN : 2296-5084

\section{Éditeur}

Université de Lausanne

\section{Édition imprimée}

Date de publication : 15 septembre 2014

ISBN : 978-2-940331-35-2

ISSN : 0014-2026

\section{Référence électronique}

Philippe Bornet et Svetlana Gorshenina, « Note sur la translittération », Études de lettres [En ligne], 2-3।

2014, mis en ligne le 15 septembre 2017, consulté le 18 décembre 2020. URL : http://

journals.openedition.org/edl/638; DOI : https://doi.org/10.4000/edl.638

(c) Études de lettres 


\section{NOTE SUR LA TRANSLITTÉRATION}

Les ethnonymes et toponymes courants, les noms de personnages historiques célèbres, ainsi que certains termes entrés dans les langues anglaise et française sont retranscrits sans signes diacritiques. Les toponymes rares, les noms de personnes qui ne s'orthographient pas de manière standardisée en anglais et en français, ainsi que des termes peu utilisés, sont translittérés selon les conventions ci-dessous. La translittération des scripts indiens (devanāgarī, tamoul), du persan et du ourdou suivent les règles de la Library of Congress. Pour le mongol et le tibétain, voir la note 1, p. 123. La translittération du russe vers le français et l'anglais est celle qu'utilisent les Cahiers du monde russe. La translittération originale des noms propres et objets géographiques dans les références bibliographiques et citations n'a pas été uniformisée. Les règles de ponctuation sont conformes aux conventions usuelles de la revue $E d L$.

\section{Table de translittération du cyrillique en alphabet latin}

dans les articles en français

\begin{tabular}{|c|c|c|c|}
\hline $\mathrm{A}-a$ & и $-i$ & $c-s$ & $\mathrm{~b}-{ }^{\prime}$ \\
\hline$\sigma-b$ & $\breve{и}-j$ & $\mathrm{~T}-t$ & ы $-y$ \\
\hline $\mathrm{B}-v$ & $\kappa-k$ & $\mathrm{y}-u$ & $\mathrm{~b}-"$ \\
\hline$\Gamma-g$ & $\pi-l$ & $\phi-f$ & $\ni-\grave{e}$ \\
\hline д -d & $\mathrm{M}-m$ & $x-h$ & $ю-j u$ \\
\hline $\mathrm{e}-e$ & $\mathrm{H}-n$ & $Ц-c$ & $я-j a$ \\
\hline$\ddot{\mathrm{e}}-\ddot{e}$ & $0-o$ & $\mathrm{\Psi}-\check{c}$ & \\
\hline ж $-\check{z}$ & $\Pi-p$ & $\amalg-\check{s}$ & \\
\hline $3-z$ & $\mathrm{p}-r$ & щ $-\check{s} \check{c}$ & \\
\hline
\end{tabular}


Table de translittération du cyrillique en alphabet latin dans les articles en anglais

\begin{tabular}{|c|c|c|c|}
\hline $\mathrm{A}-a$ & и $-i$ & $c-s$ & b - ' \\
\hline $6-b$ & й $-i$ & $\mathrm{~T}-t$ & $\mathbf{b}-y$ \\
\hline $\mathrm{B}-v$ & к $-k$ & $\mathrm{y}-u$ & $\mathrm{~b}-"$ \\
\hline$\Gamma-g$ & л $-l$ & $\phi-f$ & $\ni-\dot{e}$ \\
\hline д $-d$ & $\mathrm{M}-m$ & $\mathrm{x}-k h$ & $ю-i u$ \\
\hline $\mathrm{e}-e$ & $\mathrm{H}-n$ & $ц-t s$ & $я-i a$ \\
\hline$\ddot{\mathrm{e}}-\ddot{e}$ & $0-o$ & ч $-c h$ & \\
\hline ж-zh & $\Pi-p$ & $\amalg-s h$ & \\
\hline $3-z$ & $\mathrm{p}-r$ & щ $-s h c h$ & \\
\hline
\end{tabular}

